$\underline{\text { Research Article }}$

\title{
A study on the extent, aetiology and associated factors of dandruff in a group of medical students and the in vitro effects of antidandruff preparations
}

\author{
RK Keragala ${ }^{1}$, TD Kasunsiri ${ }^{1}$, KS Kempitiya ${ }^{1}$, \\ NN Kumarapeli ${ }^{1}$, K Kumara ${ }^{1}$, SS Gunathilaka ${ }^{1}$ \\ Sri Lankan Journal of Infectious Diseases 2020 Vol.10(2):134-145 \\ DOI: http://dx.doi.org/10.4038/sljid.v10i2.8291
}

\begin{abstract}
Introduction: Dandruff is a scalp disorder, characterized by itching and rapid skin flaking of the scalp of a person. Yeasts of the genus Malassezia are responsible for dandruff. The prevalence of dandruff in South Asia is $60.1 \%$, whereas in the world it is $50 \%$. The objectives of this study were to ascertain the prevalence, describe associated factors, isolate Malassezia sp. from dandruff samples of medical students and test the anti-fungal effects of commercially available shampoo and crude extracts of commonly used herbs against Malassezia.

Methodology: Ninety five students were chosen by systematic sampling. A self-administered questionnaire was used for data collection. Samples of skin flakes/swabs was collected from the scalp of participants. Specimens were examined using three direct microscopic methods. Fungal colonies isolated on Saborauds/Dixon Agar were identified using Gram stain and catalase test. Antifungal activity of six shampoo brands and crude extracts of eleven herbs were tested against isolated Malassezia sp. by agar well/disc diffusion method.
\end{abstract}

Results: Prevalence of dandruff was $64.2 \%$ in the study group. The typical 'spaghetti and meatball' appearance was seen in the skin flakes taken from 44 of $61(72.1 \%)$ students. Malassezia sp. was isolated only from 49 of the 61 students $(80.3 \%)$. In-vitro, anti-malassezial effect (Inhibition zone (IZ)>10mm) was observed in 4 of the 7 tested 'anti dandruff' shampoos. Crude extracts of fresh leaves of Psidium guavava (guava), flowers of Punica grantum (pomegranate) and fruits of Solanum lycopersicum (tomato) and Citrus hystrix (Kaffir lime) showed IZs > 10mm.

${ }^{1}$ Faculty of Medicine and Allied Sciences, Rajarata University of Sri Lanka

Address for correspondence: Ms Keragala R.K, Faculty of Medicine and Allied Sciences, Rajarata University of Sri Lanka Tel: +94715983749 E-mail: reshani.kaumada94@gmail.com (D) https://orcid.org/0000-0001-9658-0756

Received 8 April 2020 and revised version accepted 25 August 2020

(c) (i) use, distribution, and reproduction in any medium, provided the original author and source are credited. 
Conclusion: Prevalence of dandruff in the studied group of medical students was higher than in the Asian population. Four of the tested 'anti dandruff' shampoos and crude extracts of leaves of $P$. guavava (guava), fruits of $S$. lycopersicum (tomato), C. hystrix (kaffir lime), and flowers of $P$. grantum (pomegranate) showed an in-vitro inhibitory effect on the growth of Malassezia sp.

Keywords: dandruff, Malassezia sp., anti-fungal effects, herbals

\section{Introduction}

Dandruff is described as a scalp disorder which is characterized by itching and abnormal and rapid turnover of the outermost layer of the skin of the scalp of a person. ${ }^{1}$ The dead skin is released usually as patches and flakes of grayish white color. ${ }^{2}$ Seborrheic dermatitis (SD) and dandruff are continuation of the same condition that affects the areas which have high sebum secretion like the face, upper chest and back. ${ }^{1}$

Clinical symptoms associated with dandruff are skin flaking, itching, irritation and the feeling of a dry or tight scalp. Loosely adherent, small white or gray flakes are characteristic of dandruff whereas SD presents a yellowish, oily scale. ${ }^{3}$

There are three main factors that aid the formation of dandruff. They are fungal infections of the scalp, sebaceous secretion and individual sensitivity to substances. ${ }^{4}$

The presence of excess sebum over the scalp, gender, age, region of the scalp and microorganisms are known as the risk factors for dandruff formation. ${ }^{5}$ The most widely accepted microbial organisms are the lipophilic yeasts which belong to the genus Malassezia. Frequent exposure to sunlight, over shampooing, frequent combing, use of some cosmetic products and exposure to dust and dirt can be identified as non - microbial causes of dandruff. ${ }^{6}$

Though not a disease with adverse clinical outcomes, dandruff could make the sufferer feel selfconscious and embarrassed. It is a known fact that dandruff affects self-esteem and confidence. ${ }^{7}$ SD and dandruff affects half of the adult population due to intrinsic and environmental factors. ${ }^{1}$ Some studies have shown that $46-50 \%$ of the population is affected with dandruff., ${ }^{8,9}$ Dandruff was found to be more common among males than females. South Asia has reported a greater dandruff prevalence $\left(60.1 \%\right.$ ) compared to other regions of the world (up to $50 \%$ ) ${ }^{8,9}$,

There are no published data on the prevalence or etiology of dandruff in the Sri Lankan population. However, in the experience of the investigators, dandruff is a common problem among Sri Lankans, including university students. This study was therefore planned to assess the prevalence of dandruff among medical students, risk factors and the possibility of Malassezia sp. as a causative factor for dandruff. In addition, the in-vitro effectiveness of commercially available shampoos and crude extracts of commonly used herbs against Malassezia were tested against the isolated Malassezia sp. 


\section{Methods}

This study was conducted in the Department of Microbiology, Faculty of Medicine and Allied Sciences (FMAS), Rajarata University of Sri Lanka (RUSL), for 6 months from January 2019. Approval for the study was obtained from the Ethics Review Committee, FMAS, and RUSL (ERC/2018/39). Informed written consent was obtained from each participant at recruitment to the study.

The study was conducted in two sections.

Section 1 was a cross sectional descriptive study aimed at assessing the prevalence of dandruff, and its associated factors in third year medical students of FMAS, RUSL and isolating Malassezia sp. from students identified as having dandruff.

The study population was the third year medical students of FMAS. The sample size was calculated using the formula, $n=\mathrm{Np}(1-\mathrm{p})] /\left[\left(\mathrm{d}^{2} / \mathrm{Z}^{2}{ }_{1-\alpha / 2} *(\mathrm{~N}-1)+\mathrm{p}^{*}(1-\mathrm{p})\right]{ }^{10}\right.$

The population size (p) was 190 (number of medical students in third academic year). Hypothesized percentage of dandruff was taken as $50 \%$ as there are no available data in Sri Lanka. ${ }^{9}$ Confidence limit was taken as $10 \%$. The calculated minimum sample size was 87 for $99 \%$ confidence interval. With $10 \%$ correction for the non-consenting participants, a minimum sample of 95 was targeted and students were recruited according to systematic random sampling technique and alternatively from their University index number.

A questionnaire based study, clinical examination of the scalp, specimen collection and processing were done according to the following methods.

\section{Questionnaire}

A self-administered questionnaire was given for the collection of data. The questionnaire included demographic data, assessment of symptoms of dandruff, availability of the risk factors, and the effects of dandruff on the participant's lives according to their point of view. The clinical severity of dandruff was estimated using Adherent Scalp Flaking Score (ASFS) on the scalp using a scale from 1 to 5 depending on the appearance of skin flakes. The investigators were trained on the use of ASFS by the supervisor under the guidance of the dermatology unit. The scores on 8 zones (right frontal, left frontal, right parietal/temporal, left parietal/temporal, right occipital and left occipital) of scalp were individually measured and recorded in a specially designed sketch of sub regions of the scalp, and the total score was recorded. ${ }^{9}$ The severity of dandruff was categorized as follows, Mild dandruff when ASF score was 11-20, Moderate dandruff when the ASF score was 21-30 and severe dandruff when the ASF score was $>30 .{ }^{9}$

\section{Clinical specimen collection and processing}

\section{Participants with visible skin flakes}

Easily detachable skin flakes were carefully collected from each participant from selected sites of the scalp using sterilized epilation forceps. ${ }^{2,11}$ The specimen was then transferred onto dark sampling paper. Each sample was labelled with the participant's serial number and date of collection of the sample and transported to the laboratory for processing. 


\section{Participants without visible skin flakes}

Sterile cotton swabs which were autoclaved were rubbed onto the scalp surface (between the hairs) in a zigzag pattern, to cover a total surface of $4 \mathrm{~cm}^{2}$ in a non-overlapping manner. ${ }^{11}$ The swab was then placed in a sterile test tube and transferred to the laboratory for processing

\section{Specimen processing and analysis}

\section{Direct microscopy}

A drop of $10 \%$ potassium hydroxide, $\mathrm{KOH}$ with blue parker ink and $1 \%$ eosin were introduced onto a slide containing the sample and covered with a cover slip. ${ }^{11}$ The sample was then heated over a Bunsen flame to remove bubbles. The slides were viewed using x10 and x40 objectives with closed iris diaphragm of the lens of the condenser.

\section{Culture}

Small amounts of the samples collected were introduced into Petri dishes containing Saboraud Dextrose Agar (SDA) and Dixon's agar using sterile forceps. The Petri dishes were labelled and incubated at $37^{\circ} \mathrm{C}$, up to a week. ${ }^{12,13}$

\section{Gram stain}

Gram stain was done on smears of the pure culture obtained after one weeks of incubation at $37^{\circ} \mathrm{C}$.

Section 2 was the in vitro assessment of antifungal activity of commercially available shampoo and herbal extracts against Malassezia sp.

Using a sterile loop, 3 to 5 colonies taken from subcultures of isolated Malassezia sp. were mixed in $5 \mathrm{ml}$ of distilled water and turbidity was adjusted to the $0.5 \mathrm{McF}$ arland standard. The yeast cells were inoculated on to the agar surface using a sterile cotton swab. A well grown culture of an isolated Malassezia sp. on Dixon agar medium was used for testing antifungal activity. Both disc diffusion method and well diffusion methods were used.

Commercially available $2 \%$ ketoconazole (Jenzen Cillag ltd), was used as the control, in the well diffusion method and the same suspension soaked in filter paper discs (Whatman no.1, $15 \mathrm{~mm}$ diameter), was used as the control in the disc diffusion method.

\section{Agar well diffusion method}

The agar plate surface was inoculated by spreading one $\mu \mathrm{L}$ of the turbidity adjusted inoculum over the entire agar surface using a sterile cotton swab. A well with a diameter of $10 \mathrm{~mm}$ was punched aseptically using a sterile cork borer and $10 \mu \mathrm{L}$ of each test compoundlcrude extract without dilution was added to the well. In addition, $10 \mu \mathrm{L}$ of $2 \%$ ketoconazole and $(10 \mu \mathrm{L}$ distilled water) were placed in similar wells as positive and negative controls respectively. The agar plates were incubated at $37^{\circ} \mathrm{C}$ for five days to test for the antifungal effect. The diameter of the zone of inhibition was measured across the centre. A diameter of $>10 \mathrm{~mm}$ was taken as a significant anti malassezial effect. 


\section{Agar disc diffusion method}

Dixon's agar plates were inoculated by spreading Malassezia yeast cells over the entire agar surface using a sterile cotton swab. Then, filter paper discs (Whatman no.1, $15 \mathrm{~mm}$ diameter), containing the test compound at a $100 \%$ concentration, were placed on the agar surface. The Petri dishes were incubated at $37^{\circ} \mathrm{C}$ for 48 hours. In addition, discs containing ketoconazole and distilled water were placed on the media as positive and negative controls respectively.

\section{Antifungal effects of shampoo}

The shampoos used in the study were popular brands in the Sri Lanka market (names not disclosed to avoid any commercial implication). The tested shampoo brands were categorized into 2 groups as shown in Table 1.

Table 1: Categories and constituents of shampoos

\begin{tabular}{|l|l|l|l|}
\hline Anti-dandruff shampoo & Non 'anti dandruff' shampoo \\
\hline Brand A & Cetrimide & Brand 1 & $\begin{array}{l}\text { Sodium laureth sulphate, , Dimethicone, } \\
\text { Glycol distearate }\end{array}$ \\
\hline Brand B & Tea tree oil, Grape seed, Aloe & Brand 2 & Bacopa (Lunuwila) \\
\hline Brand C & Lunuwila extract, Fenugreek, Argan oil & Brand 3 & $\begin{array}{l}\text { Sodium laureth sulphate, Dimethiconol, } \\
\text { Cocamidopropyl betaine }\end{array}$ \\
\hline Brand D & $\begin{array}{l}\text { Chlorhexidine gluconate 2\%, } \\
\text { Ketoconazole 1\% }\end{array}$ & \\
\hline Brand E & Godapara extract & & \\
\hline Brand F & Climbazole & & \\
\hline Brand G & Tea tree oil, Zinc Prythion & \\
\hline
\end{tabular}

The tested shampoo with the active ingredient and/or the herbal extracts contained in them according to the manufacturers' notes.

\section{Antifungal effect of herbs}

Herbs tested for anti-fungal effects in the study are shown in Table 2. The herbs were authenticated at the National herbarium, Royal Botanical Gardens, Peradeniya. 
Table 2: Herbs tested in the study

\begin{tabular}{|c|c|c|c|c|}
\hline \multirow{2}{*}{ Herbal part } & & \multicolumn{3}{|c|}{ Name of herb } \\
\cline { 3 - 5 } & & English & Sinhala & Tamil \\
\hline Leaves & Azadirachta indica & Neem & Kohomba & Veppai \\
\hline & Elaeocarpus serratus & Ceylon olive & Veralu & Karamaram \\
\hline & Psidium guvava & Guava & Pera & Caitịam koyyā \\
\hline & Aloe vera & Aloe & Komarika & Karrāaaiai \\
\hline & Bacopa monnieri & Water hyssop & Lunuwila & Nīrppirami \\
\hline & Punica grantum & Pomegranate & Delum & Madulai \\
\hline Flowers & Punica grantum & Pomegranate & Delum & Madulai \\
\hline & Dillenia retusa & $*$ & Godapara & Naiteku \\
\hline & Citrus aurantiifolia & Lime & Dehi & Campas a \\
\hline & Solanum lycopersicum & Tomato & Thakkali & Takkāai \\
\hline & Dillenia triquetra & $*$ & Diyapara & Naiteku \\
\hline & Citrus hystrix & Kaffir lime & Kudalu dehi & Nardanga \\
\hline
\end{tabular}

*No English names are available as these plants are endemic to Sri Lanka

The collection of herbs was done between 1.3. 2019 to 10.3. 2019. Fresh leaves, flowers and fresh fruits were washed using flowing water and air dried for 20 minutes to evaporate water drops. Ten grams of selected parts of each herb was weighed and then ground separately using a mortar and pestle. The pulps which were formed by each sample were squeezed in cheese cloths and the filtrate considered as a $100 \%$ extract of the plant.

\section{Results}

\section{Section 1}

Of the 95 students sampled during the period of the study, $61(64.2 \%)$ had dandruff of whom 42 (68.9\%) were females. Of the students with dandruff, $54(88.5 \%)$ had mild dandruff and 7 (11.5\%) moderate dandruff. Table 3 gives the percentage and frequency of students having dandruff of different grades of severity.

Table 3: Severity of dandruff according to ASFS grading

\begin{tabular}{llll}
\hline Clinical category & \multirow{2}{*}{ ASF Score } & \multicolumn{2}{c}{ Participants } \\
\cline { 2 - 4 } & & Number & $\%$ \\
\hline Mild dandruff & $1-10$ & 21 & 34.4 \\
\cline { 2 - 4 } & $11-20$ & 33 & 54.1 \\
\hline Moderate dandruff & $21-30$ & 7 & 11.5 \\
\hline Severe dandruff & $>30$ & 0 & 0 \\
\hline
\end{tabular}


Table 4: Significant values of associated risk factors of dandruff

\begin{tabular}{|c|c|c|c|}
\hline Associated factors & $\begin{array}{l}\text { Number of } \\
\text { participants with } \\
\text { dandruff }\end{array}$ & $\begin{array}{c}\text { Number of } \\
\text { participants } \\
\text { without dandruff }\end{array}$ & $P$ value \\
\hline Excessive sweating & 10 & 13 & 0.37 \\
\hline Regular physical exercise & 35 & 15 & 0.64 \\
\hline Shampoo use & 47 & 33 & 0.35 \\
\hline Soap use & 10 & 9 & 0.56 \\
\hline \multicolumn{3}{|l|}{ Frequency of bathing (per week) } & \multirow{8}{*}{0.97} \\
\hline - 1 & 2 & 0 & \\
\hline - 2 & 2 & 1 & \\
\hline - 3 & 14 & 7 & \\
\hline - 4 & 19 & 14 & \\
\hline - 5 & 6 & 3 & \\
\hline - 6 & 2 & 2 & \\
\hline - 7 & 11 & 12 & \\
\hline \multicolumn{3}{|l|}{ Bathing time } & \multirow{5}{*}{0.37} \\
\hline - Morning & 3 & 2 & \\
\hline - Day time & 8 & 5 & \\
\hline - Afternoon & 34 & 26 & \\
\hline - Night & 11 & 6 & \\
\hline Blow dryer use & 18 & 5 & 0.21 \\
\hline Conditioner use & 31 & 16 & 0.48 \\
\hline Leave on conditioner & 3 & 8 & 0.98 \\
\hline Chemically changed & 9 & 10 & 0.98 \\
\hline \multicolumn{3}{|l|}{ Chemically processing times } & \multirow{7}{*}{1.00} \\
\hline - Never & 47 & 29 & \\
\hline - Once a week & 1 & 0 & \\
\hline - Once a month & 1 & 1 & \\
\hline - Once every 6 months & 1 & 1 & \\
\hline - Once a year & 4 & 4 & \\
\hline \multirow{2}{*}{$\begin{array}{l}\bullet \quad \text { Once ever } \\
\text { Dye hair }\end{array}$} & 2 & 4 & \\
\hline & 2 & 2 & 0.02 \\
\hline
\end{tabular}

\section{Microscopy}

The 'spaghetti and meatball' appearance, typical for $\mathrm{KOH}$ smears of Malassezia sp. was seen in 44 of $61 \quad(72.1 \%)$ skin flake samples (Figure 1a). Of the 61 samples, Malassezia sp. was isolated from 49 $(80.3 \%)$. None of the skin swabs (0/34) were positive for Malassezia $s p$. Figure $1 \mathrm{~b}$ shows a Gram stained smear of isolated Malassezia sp.

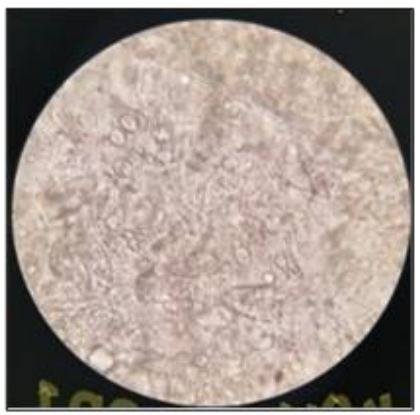

Figure 1a: Spaghetti and meatball appearance in $\mathrm{KOH}$ preparation of dandruff

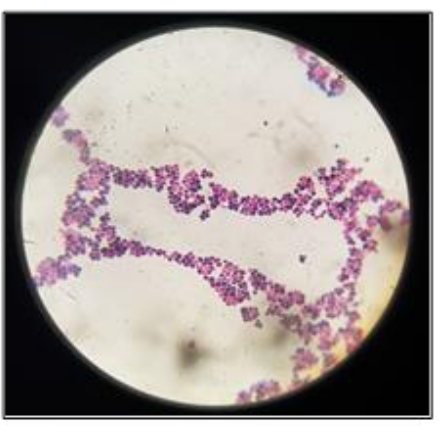

Figure Ib: Gram stained smear of Malassezia sp. isolated from dandruff 


\section{Section 2}

In-vitro, anti-malassezial effect (IZ >10mm) was observed in 4 of the 7 tested 'anti dandruff' shampoos. One of the three non anti dandruff shampoos showed anti-fungal effects against Malassezia sp. (Table 5). In-vitro, anti-malassezial effect (IZ $>10 \mathrm{~mm}$ ) was demonstrated by 5 of the 11 tested crude extracts of herbs (Table 6).

Table 5 : Inhibition zones of tested shampoo

\begin{tabular}{|l|l|c|c|c|c|}
$\begin{array}{l}\text { Tested } \\
\text { shampoo }\end{array}$ & Active ingredients/herbal extract & \multicolumn{2}{c}{$\begin{array}{c}\text { IZ of test } \\
\text { product } \\
(\mathbf{m m})\end{array}$} & $\begin{array}{c}\text { IZ of 2\% } \\
\text { ketoconazole } \\
(\mathbf{m m})\end{array}$ \\
\hline & Well & Disc & Well & Disc \\
\hline Brand A & Cetrimide & 4 & 3 & 16 & 15 \\
\hline Brand B & Tea tree oil, Grape seed, Aloe & 5 & 7 & 16 & 15 \\
\hline Brand C & Bacopa , Fenugreek, Argan oil & 15 & 15 & 18 & 18 \\
\hline Brand D & Cholorhexidine, Ketoconazole 1\% & 14 & 20 & 18 & 18 \\
\hline Brand E & Dillenia retusa extract & 20 & 16 & 16 & 17 \\
\hline Brand F & Climbazole & 5 & 4 & 18 & 17 \\
\hline Brand G & Tea tree oil, Zinc Prythion & 30 & 24 & 19 & 16 \\
\hline Brand 1 & $\begin{array}{l}\text { Sodium Laureth Sulphate, Dimethicone, Glycol } \\
\text { disterate }\end{array}$ & 4 & 5 & 16 & 17 \\
\hline Brand 2 & Bacopa & 16 & 15 & 18 & 17 \\
\hline Brand 3 & Sodium Laureth Sulphate, Dimethiconol, & 3 & 3 & 19 & 16 \\
\hline & Cocamidopropyl Betaine & & & & \\
\hline
\end{tabular}

Table 6: Inhibition zones of herbal preparations

\begin{tabular}{|c|c|c|c|c|c|c|}
\hline \multicolumn{2}{|l|}{ Tested herbs } & \multirow[t]{2}{*}{$\begin{array}{l}\text { Active } \\
\text { ingredients/herbal } \\
\text { extract }\end{array}$} & \multicolumn{2}{|c|}{$\begin{array}{l}\text { IZ of test } \\
\text { product } \\
(\mathrm{mm})\end{array}$} & \multicolumn{2}{|c|}{$\begin{array}{c}\text { IZ of } 2 \% \\
\text { Ketoconazole } \\
(\mathbf{m m})\end{array}$} \\
\hline & & & Well & Disc & Well & Disc \\
\hline & & Preparation & & & & \\
\hline Azadirachta indica & Neem & Crude extract of leaves & 0 & 0 & 18 & 17 \\
\hline $\begin{array}{l}\text { Elaeocarpus } \\
\text { serratus }\end{array}$ & Ceylon olive & Crude extract of leaves & 6 & 0 & 17 & 17 \\
\hline Psidium guajava & Guava & Crude extract of leaves & 15 & 5 & 18 & 18 \\
\hline Aloe vera & Aloe & Crude extract of leaves & 0 & 0 & 18 & 17 \\
\hline Bacopa monnieri & Water hyssop & Crude extract of leaves & 9 & 0 & 19 & 18 \\
\hline Punica grantum & Pomegranate & Crude extract of leaves & 11 & 6 & 17 & 16 \\
\hline Punica grantum & Pomegranate & $\begin{array}{l}\text { Crude extract of } \\
\text { flowers }\end{array}$ & 11 & 9 & 16 & 16 \\
\hline Dillenia retusa & Godapara & Crude extract of fruits & 3 & 2 & 18 & 16 \\
\hline $\begin{array}{l}\text { Citrus } \\
\text { aurantiifolia }\end{array}$ & Lime & Crude extract of fruits & 6 & 0 & 19 & 17 \\
\hline $\begin{array}{l}\text { Solanumly } \\
\text { copersicum }\end{array}$ & Tomato & Crude extract of fruits & 12 & 0 & 17 & 17 \\
\hline Dillenia triquetra- & Diyapara & Crude extract of fruits & 0 & 0 & 18 & 16 \\
\hline Citrus hystrix & Kaffir lime & Crude extract of fruits & 11 & 0 & 18 & 18 \\
\hline
\end{tabular}




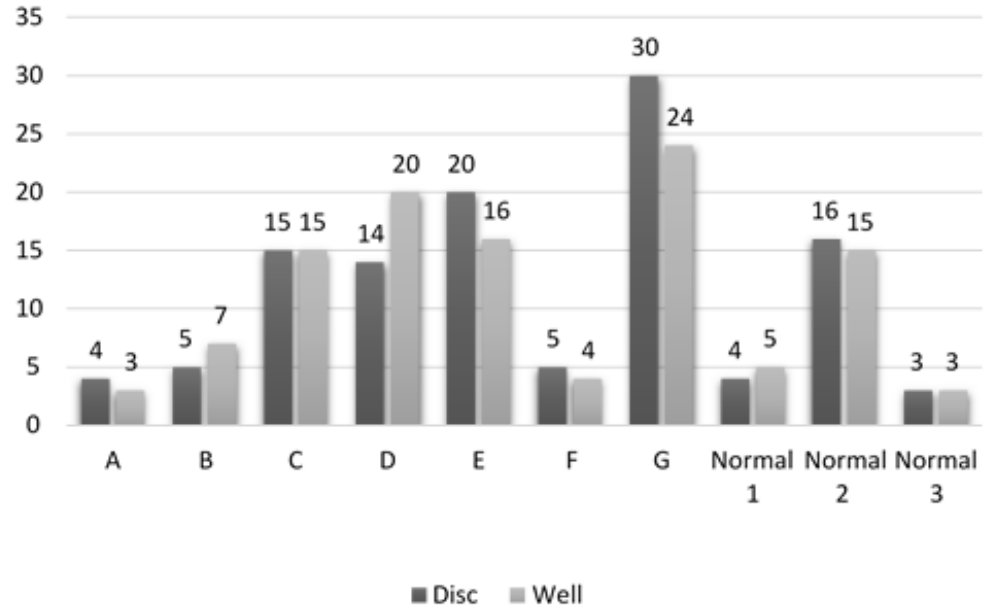

Figure 2: Comparison of the inhibition zones shown by the tested shampoo

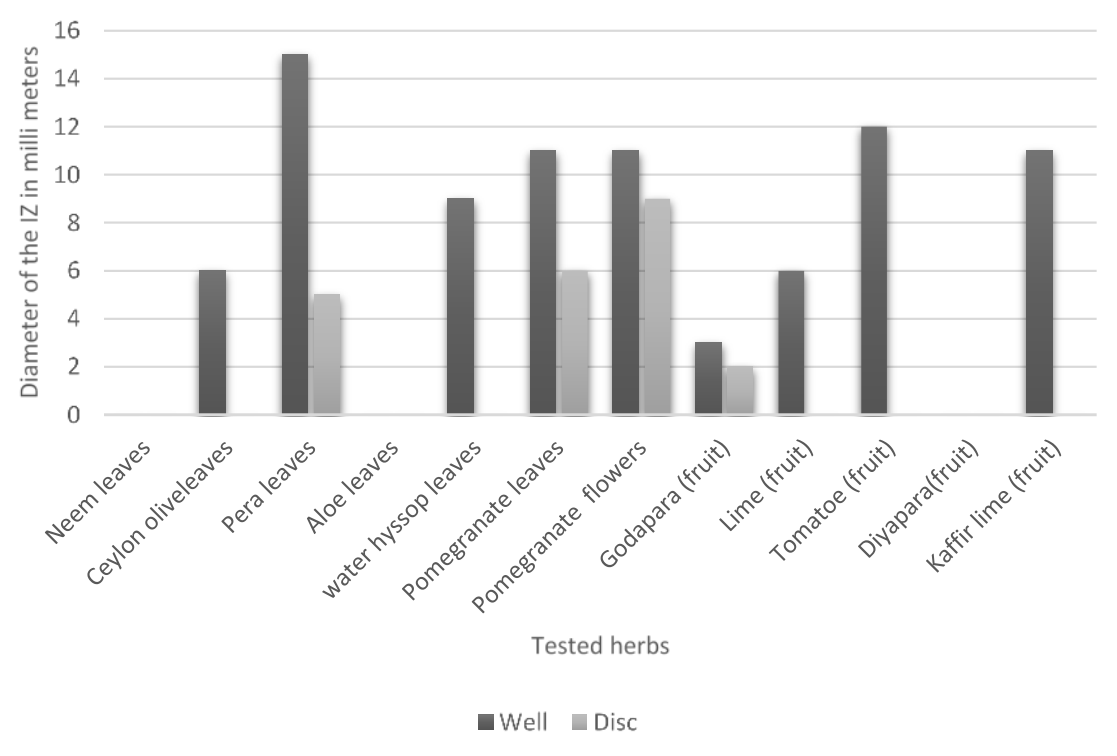

Figure 3: Comparison of the inhibition zones shown by the crude extracts of herbs 


\section{Discussion}

The prevalence of dandruff in the tested population is $64.2 \%$. Though previous studies are not available in Sri Lanka, one study done in the Asian region reported a prevalence of dandruff of $60.1 \%{ }^{8}$ The symptoms of dandruff was similar to the present study. Dandruff is reported as being more prevalent among males than females. In a study done by Misery et al (2013) the prevalence among male participants was $20.7 \%$ compared to $12.8 \%$ in females. ${ }^{13}$ In contrast, more females $(63.9 \%)$ were found to have dandruff in the present study. The reasons for this difference need to be studied further. Only the use of hair dyes showed a statistically significant association with the presence of dandruff. Previous reports of an association between hair dye use and dandruff could not be found. The irritation of the scalp skin due to frequent use of hair dyes leading to increased susceptibility of skin for the growth of Malassezia sp. may explain this association

The organism was identified in the current study by its typical appearance in the $\mathrm{KOH}$ preparation and growth on Dixon agar medium, which is specific for yeasts of Malassezia genus. Species identification could not be carried out due to financial constraints.

Sample collection was done using the method described in Bhattacharyya et al.,(2017). ${ }^{10}$ This method was selected because there is a posibility that Malassezia sp. could be present in normal scalp skin (as a member of the normal flora), even in the absence of dandruff. ${ }^{14}$ However, in the present study Malassezia sp were not isolated from participants without dandruff who were therefore included as a control group (Table 4).

Both well diffusion method and disc diffusion methods were used in assessing antifungal activity. Though disc diffusion method is used in testing anti-bacterial effects of drugs, the well diffusion method is considered better for assessing the effects of aqueous preparations. Although both methods were used in the current study, the results of the well diffusion method were used in analysis as it is the recognized method for obtaining the inhibitory effects of aqueous preparations.

Various commercially available products as well as home remedies are used by people for treatment of dandruff. Some authors have referred dandruff as the most commercially exploited skin condition. ${ }^{13} \mathrm{We}$ have tested the anti malassezial effect of some commercially available preparations and commonly used herbal preparations. Interestingly, while some 'anti dandruff' shampoos (3/7) did not show in vitro anti malassezial effect, one 'non anti dandruff' shampoo showed significant anti malassezial activity. The current study assessed only the vitro activity of the tested compounds. The absence of in vitro anti malassezial activity in the advertised 'anti dandruff' shampoo is worthy of note. Three shampoo brands (Brand C, E, and brand 2) in which herbal extracts of 'Water hyssop' and 'Godapara' were stated as main ingredients, showed inhibition zones $>10 \mathrm{~mm}$. However, the crude extracts of the same herbs showed inhibition zones of only $9 \mathrm{~mm}$ and $3 \mathrm{~mm}$ respectively. Since the manufacturers did not state the method of extraction, the discrepancy cannot be explained at this stage. Further studies on the active ingredients in the herbs are required to determine the active compounds and most effective method(s) of extraction to maximize effectiveness of the products used for this purpose.

The current study assessed only the in vitro activity and did not study the clinical effectiveness of the tested products. Further studies are indicated to determine clinical effectiveness of commercially available shampoos as well as herbal remedies. In depth studies including clinical trials to test the efficacy and 
safety of herbal preparations may lead to the discovery of new products with better 'anti dandruff' properties.

\section{Conclusion}

Prevalence of dandruff in the studied group of medical students was higher than the Asian population. Four of the tested 'Anti dandruff' shampoos, crude extracts of leaves of Pera, fruits of Kudalu and Thakkali, and flowers of Delum showed in-vitro inhibitory effects $(>10 \mathrm{~mm}$ Inhibition Zones) on the growth of Malassezia sp.

\section{Acknowledgements}

Dean of Faculty of Medicine and Allied Sciences, Rajarata University of Sri Lanka, Academic staff of Department of Community Medicine, Head, academic staff, and non-academic staff of Department of Microbiology, Dr. S.P.A.S. Senadheera, Department of Biochemistry and all the participants of the study are acknowledged.

Conflicts of Interests: The authors declare that there are no conflicts of interests.

Ethical statement: Ethical clearance for the study was obtained from Ethics Review Committee, Faculty of Medicine and Allied Sciences, Rajarata University of Sri Lanka (ERC/2017/39)

\section{References}

1. Borda LJ, Wickramanayake TC. Seborrheic dermatitis and dandruff: a comprehensive review. $J$ Clin Investig Dermatology. 2015; 3: 2. doi: https://doi.org/10.13188/2373-1044.1000019

2. Shu'aibu I, Hauwa S, Fatima UM , Muhd MM. Isolation and identification of Malassezia globosa, associated with dandruff among female students of Gombe State University. Greener J Microbiol Antimicrob. 2013; 1:001-6. doi: https://doi.org/10.15580/GJMA.2013.1.080913827

3. Grimalt R. A practical guide to scalp disorders. Journal of Investigative Dermatology Symposium Proceedings. 2007. doi: https://doi.org/10.1038/sj.jidsymp.5650048

4. Manuel F, Ranganathan S. A new postulate on two stages of dandruff: a clinical perspective. Int J Trichology . 2011;3:3-6. doi: https://doi.org/10.4103/0974-7753.82117

5. Ranganathan S, Mukhopadhyay T. Dandruff: The most commercially exploited skin disease. Indian J Dermatol. 2010; 55:130-134. doi: https://doi.org/10.4103/0019-5154.62734

6. Bhattacharyya A, Jain N, Prasad S et al. Evaluation of therapeutic potential of VB-001, a leave-on formulation, for the treatment of moderate adherent dandruff. BMC Dermatol. 2017; 17:5. doi: https://doi.org/ 10.1186/s12895-017-0058-5

7. Saxena R, Mittal P, Clavaud C et al. Comparison of healthy and dandruff scalp microbiome reveals the role of commensals in scalp health. Front Cell Infect Microbiol. 2018; 8:346. doi: https://doi.org/ 10.3389/fcimb.2018.00346

8. Kindo AJ, Sophia SKC, Kalyani J , Anandan S. Identification of Malassezia species. Indian J Med Microbiol . 2004; 22:179-81. PMID: 17642728

9. Cheesbrough M. Fungal pathogens. District laboratory practice in tropical countries part 2 :Cambridge University Press; 2005.

10. Kadam P, Bhalerao S. Sample size calculation. Int J Ayurveda Res. 2010; 1: 55-57. doi: https://doi.org/10.4103/0974-7788.59946

11. Bergler-Czop B and Brzezińska-Wcisło L. Dermatological problems of the puberty. Postepy Dermatol Alergol. 2013; 30: 178-187. doi: https://doi.org/10.5114/pdia.2013.35621 
12. Misery L., Rahhali N., Duhamel A., Taieb C. (2013). Epidemiology of dandruff, scalp pruritus and associated symptoms. Acta Derm. Venereol.2011; 93:80-81.

doi: https: //doi.org/ 10.2340/00015555-1315

13. Ashbee H.R. and Bond R. Malassezia species and immunity: Host-pathogen interactions. In: Boekhout T., Mayser P., Guého-Kellermann E, Velegraki A(eds). Malassezia and the skin. Springer, Berlin, Heidelberg, 2010: 139-173. 